\title{
América Latina y el Caribe frente al nuevo escenario cubano-norteamericano: ¿continuidad o cambios?
}

\author{
Carlos Oliva CAMPOS \\ Presidente de la Cátedra Honorífica Bolivariana \\ Facultad de Filosofía e Historia \\ Universidad de La Habana \\ carlosoc@ffh.uh.cu
}

\begin{abstract}
RESUMEN
Con la decisión conjunta de los Presidentes de Estados Unidos y Cuba el 14 de diciembre de 2014, de iniciar un proceso de negociaciones para restablecer las relaciones diplomáticas bilaterales, se abre un nuevo momento histórico para el hemisferio, en el cual América Latina y el Caribe asumen el nuevo proceso bajo condiciones de mayor autonomía, soberanía e independencia. Estados Unidos y el Sistema Interamericano deben trascender sus poco funcionales visiones históricas, para poder trabajar de forma conjunta con la emergente institucionalidad latinoamericana y caribeña si se desea realmente pasar a construir una nueva y positiva relación, so pena de perder mayores espacios en la región.
\end{abstract}

Palabras clave: relaciones Cuba - Estados Unidos; Cumbre de las Américas; relaciones Estados Unidos América Latina; OEA; CELAC.

\section{Latin America and the Caribbean vis-à-vis the New Cuban - North American Scenario: Change or Continuity?}

\begin{abstract}
With the $14^{\text {th }}$ December 2014 decision to initiate a new process of negotiations leading to the reestablishment of diplomatic relations, the Presidents of the United States and Cuba gave way to a new historical moment for the hemisphere by virtue of which Latin America and the Caribbean region might perform a role in the process under conditions of greater autonomy, sovereignty and independence. If a new and positive relation wants to be built the United States and the Inter-American system shall supersede their historically little functional visions so that greater spaces in the region are not lost.
\end{abstract}

Key words: US-Cuban relations; Summit of the Americas; US-Latin America relations; OAS; CELAC. 


\title{
América Latina e o Caribe frente ao novo cenário cubano- norteamericano: continuidade ou mudanças?
}

\begin{abstract}
RESUMO
Com a decisão conjunta dos Presidentes de Estados Unidos e Cuba o 14 de dezembro de 2014, de iniciar um processo de negociações para restabelecer as relações diplomáticas bilaterais, abre-se um novo momento histórico para o hemisfério, no qual América Latina e o Caribe assumem o novo processo baixo condições de maior autonomia, soberania e independência. Estados Unidos e o Sistema Interamericano devem transcender suas pouco funcionais visões históricas, para poder trabalhar de forma conjunta com a emergente institucionalidade latino-americana e caribenha se deseja realmente passar a construir uma nova e positiva relação, sob pena de perder maiores espaços na região.
\end{abstract}

Palavras-chave: relações Cuba - Estados Unidos; Cimeira das Américas; relações Estados Unidos - América Latina; OEA; CELAC.

\section{REFERENCIA NORMALIZADA}

Oliva Campos, Carlos (2015) “América Latina y el Caribe frente al nuevo escenario cubano-norteamericano: ¿continuidad o cambios?”. Geopolítica(s). Revista de estudios sobre espacio y poder, vol. 6, núm. 1, 11-37.

SUMARIO: Introducción. 1. América Latina y el Caribe frente al nuevo escenario cubano-estadounidense. 2. Los factores que propiciaron la definitiva reinserción de Cuba en la comunidad regional. 3. Relaciones y no relaciones entre México y Cuba: los claroscuros del camino de la reinserción regional. 4. Cuba y la nueva configuración socio-política regional. 5. Cuba, Estados Unidos y la VII Cumbre de las Américas. 6. Las relaciones entre Estados Unidos, América Latina y el Caribe: presente y futuro. Bibliografía.

\section{Introducción}

El 17 de diciembre de 2014 - ya hay quienes le denominan el 17-D— se abrió un nuevo capítulo para la historia de la nación cubana y de su conflicto histórico con Estados Unidos. Casualidad o intencionalidad, coincidió con la celebración de San Lázaro (Babalú-Ayé), uno de los santos de mayor arraigo popular en la isla. El acontecimiento que determinó comenzar a hablar de un antes y un después es harto conocido ya, la simultánea declaración pública de los Presidentes Barack Obama y Raúl Castro de anunciar el intercambio de prisioneros largamente esperado y la -no esperada por muchos- decisión de iniciar un proceso de conversaciones para restablecer las relaciones diplomáticas bilaterales.

Salvo aquellos, muy contados al parecer, implicados directamente en las secretas negociaciones que se desarrollaron nada menos que durante 18 meses en algún lugar de Canadá, los que tratamos de seguir los enigmas de tan complejo conflicto esperábamos que se alcanzara en algún momento un acuerdo - por razones humanitarias, esencialmente - para proceder a intercambiar a Alan Gross por los tres luchadores antiterroristas cubanos, Ramón Labañino, Antonio Guerrero y Gerardo 
Hernández Nordelo, que quedaban prisioneros en Estados Unidos. Porque, si bien Obama había planteado durante su campaña electoral que había que revisar las políticas hacia Cuba, mediaron cinco largos años durante los cuales predominaron:

- el mantenimiento del mismo proyecto de deslegitimación interna del gobierno cubano y acreditación de una oposición política alternativa, liderado por el Departamento de Estado, actores de la "Comunidad de Inteligencia" y la participación activa de una figura muy de moda, los sub-contratistas, sin obtener los resultados esperados;

- una persecución constante a toda operación financiera o comercial de la isla, en función de acentuar el bloqueo existente;

- la convincente y esperada derrota demócrata en las elecciones legislativas de noviembre de 2014;

- y el despliegue de la estrategia electoral para que Hillary Clinton sea nominada como candidata a la presidencia de Estados Unidos para el 2016, lo que demanda entre otros muchos factores, de una recomposición de las bases electorales del Partido Demócrata.

Por eso resultaron tan definitorias las palabras del Presidente estadounidense al afirmar que "en lo que se refiere a Cuba ponemos fin a una política que superó su fecha de caducidad hace mucho tiempo. Cuando lo que hacemos no funciona durante cincuenta años es tiempo de adoptar un nuevo enfoque [...] Nuestro cambio de política respecto a Cuba puede poner término a un legado de desconfianza en nuestro hemisferio [...] y este año el Congreso debe poner fin al embargo" (Avila y Keneally, 2015).

Indudablemente, el reconocimiento público del fracaso de las políticas aplicadas a Cuba por más de cincuenta años otorga una victoria a la resistencia y la tenacidad con que el gobierno de la isla ha enfrentado un conflicto que ha condicionado totalmente la vida de esa nación. Hablamos de un conflicto bilateral histórico, centrado en la negación del derecho de Cuba a ser soberana e independiente, basado en criterios geopolíticos y de seguridad para Estados Unidos, en los que no puede desconocerse el hecho de que Cuba existe dentro del área geográfica de hegemonía absoluta para ese país. Es esa razón, inamovible desde el surgimiento de Estados Unidos como nación, la que determina la esencia del conflicto bilateral, planteado en términos de hegemonía vs. independencia y soberanía nacional.

El conflicto adquirió una dimensión ideológica a partir de 1959, al activar las alarmas el gobierno estadounidense por las percepciones de amenazas a su seguridad nacional con el triunfo de la Revolución cubana. La inclusión de la URSS en un conflicto de tan larga data pasó a definir una nueva geometría geopolítica que colocó al mundo al borde de una guerra nuclear cuando en octubre de 1962 la presencia de misiles nucleares en Cuba facilitó que soviéticos y estadounidenses se 
fueran a París - siempre París, como en 1898 y siempre sin los cubanos- para negociar sus escenarios geopolíticos del momento.

\section{América Latina y el Caribe frente al nuevo escenario cubano-estadounidense}

A pesar del alcance mundial del anuncio del proceso de restablecimiento de relaciones diplomáticas entre Cuba y Estados Unidos, y los innegables impactos que tiene a la hora de evaluar las relaciones internas e internacionales de la isla, hay que considerar la decisión de Obama de pasar a reacomodar — no sustituir - el enfoque que ha determinado las políticas hacia Cuba en la Posguerra Fría. Es sabido que durante todo el período previo, en tiempos de la alianza estratégica cubanosoviética, el foco de atención de las políticas estadounidenses hacia la isla estuvo centrado en el amplio activismo político internacional desplegado por el gobierno cubano. Tras la caída del Muro de Berlín, el "tema Cuba" quedó en un limbo doméstico manejado, re-direccionado hacia los asuntos internos en la isla, insistiéndose en la sustitución del sistema político cubano, aplicando los presupuestos occidentales sobre democracia y derechos humanos.

A partir de ese momento, las políticas estadounidenses parecieron tener un perfil más bajo - apostando a un colapso político interno en la isla que no llegó-, lo que propició un mayor protagonismo del poderoso lobby cubano-americano, que pasó a asumir determinados protagonismos. De ahí que la actual coyuntura, aunque no supera la perspectiva doméstica con que Obama, los Clinton y sus seguidores demócratas enfocan el "tema Cuba", sí marca un evidente reacomodo de enfoques que sobrepuso el acercamiento a la confrontación. La nueva perspectiva abre definitivamente el espacio a la búsqueda de un cambio de régimen en la isla bajo los paradigmas del soft power y el reposicionamiento estadounidense en la economía cubana.

Desde el triunfo revolucionario de enero de 1959, la región de América Latina y el Caribe se mantuvo condicionada a los vaivenes del conflicto cubanoestadounidense. Ruptura casi total de los vínculos diplomáticos, un comercio casi nulo siguiendo los dictados del bloqueo aplicado por Estados Unidos, confrontaciones político-ideológicas y muchos vaivenes en cuanto a aproximaciones coyunturales y nuevas rupturas, predominaron durante todo el período de Guerra Fría. Ya con la Posguerra Fría y los trascendentales cambios acontecidos en la región, comenzaron a desatarse nuevas dinámicas que llevaron a finales de la primera década del siglo XXI a la decisión, soberana e independiente de América Latina y el Caribe, de reinsertar plenamente a Cuba en la comunidad regional.

Como ya se avanzaba, las relaciones diplomáticas que mantienen hoy los países de América Latina y el Caribe con Cuba no son ajenas a la reconfiguración sociopolítica vivida en la región, y al dinámico replanteamiento tanto de las relaciones intralatinoamericanas y caribeñas como a la nueva inserción regional en la econo- 
mía global. Por tanto, hay que destacar que el escenario regional original, que sirvió de contexto hemisférico al conflicto cubano-estadounidense, ha sido sustituido por otro que actúa con mucho mayores márgenes de independencia frente a Estados Unidos, en particular en lo concerniente al replanteamiento de los viejos enfoques político-ideológicos sobre la isla. Por supuesto, a esto ha contribuido grandemente el proceso gradual de transformaciones que se lleva a efecto en la isla, defendiendo la perspectiva de la búsqueda del perfeccionamiento del modelo socialista, que tiene entre sus premisas importantes cambios económicos - como el creciente sector "cuenta propista" - y la mayor apertura de la economía cubana a la economía global. De ahí que la VII Cumbre de las Américas convocada por Panamá para los días 10 y 11 de abril de 2015, se proyectara de inmediato en el horizonte político como el primer gran escenario de encuentros entre todos los habitantes de este hemisferio. Siendo muy válido recordar que ya la decisión de invitar oficialmente a Cuba estaba tomada antes del 17-D. Y es que precisamente las actuales relaciones de Cuba con los países de América Latina y el Caribe ya superaron el complicado proceso histórico que los separó a inicios de los años 60 del pasado siglo. Por eso no resulta ocioso reiterar que la reinserción plena de Cuba en la comunidad regional fue decidida a partir de la voluntad política de todos los países implicados, sobreponiéndose a las interferencias de actores y factores externos, en primerísimo lugar de Estados Unidos.

Sólo para ilustrar lo afirmado, considérese que durante el 2014 —antes del 17 de diciembre-Cuba desarrolló con todo éxito la II Cumbre de la CELAC - enero-, entregando la Presidencia pro-tempore de la organización a Costa Rica. El encuentro sobresalió por una presencia record de Jefes de Estado y Gobierno de América Latina y el Caribe (29 mandatarios) y el reconocimiento general de la positiva gestión realizada por el gobierno cubano durante su año de mandato. El cónclave destacó por la aprobación colectiva de considerar a América Latina y el Caribe como zona de paz.

También durante el 2014, el gobierno cubano organizó dos encuentros cumbre de los países del ALBA-TCP. La primera, una Cumbre Extraordinaria - octubrepara debatir sobre cómo coordinar esfuerzos para contrarrestar una eventual entrada de la terrible epidemia del ébola en la región y la implementación de los necesarios planes de contingencia. La segunda Cumbre se organizó para celebrar la primera década de vida del mencionado proyecto integrador - diciembre-, gestado por los Presidentes Fidel Castro y Hugo Chávez en el año 2004. Y resta por mencionar la celebración en la isla de otro estratégico cónclave, la V Cumbre CubaCARICOM - también en diciembre-, que reafirmó la profundidad de las relaciones de la isla con sus vecinos caribeños. Como expresó Gastón Alphonso Browne, Primer Ministro de Antigua y Barbuda y Presidente de la Comunidad de Estados del Caribe (CARICOM), durante el acto inaugural de la V Cumbre Cuba-CARICOM: 
La fuerza de la solidaridad de los pueblos de la Comunidad del Caribe con Cuba se evidencia aquí y ahora con la presencia en esta capital, La Habana, de misiones diplomáticas de los 14 países independientes de la CARICOM.

De hecho, La Habana es el único lugar, además de Washington y las Naciones Unidas, donde la CARICOM está representada por la totalidad de sus Estados miembros.

Ese es el valor que conferimos a Cuba; esa es la medida de nuestro gran respeto y alta estima que sentimos por el pueblo y el gobierno de Cuba (CubaDebate, 8 de diciembre de 2014).

Por otra parte, el año marcó una importante continuidad de los Diálogos sobre la búsqueda de paz en Colombia, que se sostienen desde 2012 en La Habana entre representantes de las FARC/ERP y el gobierno de Bogotá. Cuba, junto a Noruega, actúa como garante del proceso y es facilitador del encuentro.

Restaría por agregar a las acciones político-diplomáticas señaladas que, en el propio año 2014, Cuba recibió las estratégicas visitas de los Presidentes de Rusia, Vladimir Putin, y China, Xi Jinping, ambas en el mes de julio, antes de la participación del Presidente Raúl Castro en la Cumbre China-América Latina que se celebró en Brasil. Tal mención, nos habla no sólo de la solidez de la reinserción regional de la isla, sino de la nueva configuración de sus relaciones internacionales.

Y como colofón de esta panorámica introductoria, en fecha también previa al 17 de diciembre de 2014, las autoridades panameñas y cubanas habían dialogado sobre la necesidad de la presencia de Cuba en la Cumbre de Panamá, recibiendo el gobierno cubano el 5 de diciembre la invitación formal para asistir al cónclave.

\section{Los factores que propiciaron la definitiva reinserción de Cuba en la comuni- dad regional}

Indudablemente, el capítulo final para hacer efectiva la plena reinserción de Cuba en la comunidad regional comenzó a escribirse con la apertura del llamado período de Posguerra Fría. A pesar de significar para Cuba - o tal vez debido a eso- la gran paradoja de iniciarlo con la debacle de su economía, condicionada a una cerrada relación de décadas con la URSS y el campo socialista este-europeo, las miradas de Cuba hacia la región y de la región hacia Cuba pasaron a ser muy diferentes. De ahí la importancia de repasar algunos eventos que influyeron directamente en la definición del nuevo escenario hemisférico y, en consecuencia, contribuyeron a los profundos cambios que facilitaron la reconfiguración socio-política que vive hoy América Latina. En ese nuevo contexto hemisférico se alcanzó la reinserción plena de Cuba en la comunidad regional.

El primero de esos eventos está relacionado con las variaciones ocurridas con América Latina y el Caribe, como región, dentro de la agenda global de la política 
exterior de Estados Unidos. Es bien conocido que como parte de las transformaciones, las nuevas prioridades y agendas que emergieron ante el nuevo escenario internacional, la región de América Latina y el Caribe fue movida a un segundo nivel de atención, ya que el foco de interés pasó a centrarse - por razones geopolíticas y geoeconómicas - en otras regiones como el Medio Oriente y Asia; lo cual no significó, como erróneamente creyeron algunos, que esta área perdiera su histórico y estratégico lugar en la matriz global de la política exterior estadounidense. Las burocracias especializadas - esas que mayormente son anónimas y sobreviven a las administraciones - readecuaron sus agendas y rediseñaron las políticas que aplicaron todas las instituciones y agencias del gobierno estadounidense encargadas de la región. Ha habido reclamos y nostalgias, pero no vacíos. No han faltado nuevas políticas ni decisiones de impacto regional, léase los diferentes proyectos de Libre Comercio - expresión de consensos bipartidistas entre Bush senior y Clinton-; la reconfiguración de la seguridad de Norteamérica post 11-S - con implicaciones directas sobre México y Canadá, principalmente-; la regionalización de la política anti-drogas estadounidense, con sus dos caras ante el problema; la reactivación de la IV Flota; el proyecto de "diplomacia transformacional" de Condolezza Rice, que la ha sobrevivido; la continuidad de las políticas hacia Cuba y Venezuela, administración tras administración, hasta al archimencionado 17-D.

Lo que no significa que la llamada "agenda interamericana" haya sufrido importantes cambios y reacomodos a partir de la Posguerra Fría. Repasemos algunos de los más significativos:

- El fin de la URSS y sus aliados socialistas dejó sin efectos las amenazas que justificaron tantas decisiones militares, económicas, políticas y de inteligencia, que marcaron las relaciones interamericanas durante los largos años de Guerra Fría. De hecho, el gran argumento de luchar contra el comunismo fue sustituido por nuevos temas, como la lucha por la democracia y la defensa de los derechos humanos y contra el narcotráfico. Tal vez la intervención militar estadounidense en Panamá de diciembre de 1989, devino en ejemplo de los nuevos tiempos y el peor de los cierres para esa trágica etapa.

- Dentro de ese gran tema, hay que particularizar la disolución de la alianza estratégica que sostuvieron Cuba y la URSS, quedando sin efectos las percepciones de amenazas a la seguridad nacional estadounidense provenientes de la isla.

- El fin de la presencia soviética en el hemisferio se conjugó con otros factores como el cese de los conflictos armados en Centroamérica para colocar en una crisis, al parecer definitiva, a la lucha armada como alternativa a seguir por las fuerzas opositoras y los movimientos irregulares de la región. El fortalecimiento de tales percepciones fue legitimando la lucha política 
por vía electoral como medio fundamental para la búsqueda de alcanzar gobiernos y conquistar el poder.

- La extensión por toda la región, durante la década de los años 90 del siglo $\mathrm{XX}$, de gobiernos neoliberales aliados de Estados Unidos, en correspondencia con las tendencias imperantes en la economía global. Bajo esas condiciones, las relaciones interamericanas parecieron transitar por caminos de estabilidad política, alianzas y la cooperación a partir de los diferentes proyectos de Libre Comercio lanzados por Estados Unidos.

Sin embargo, si bien la "agenda interamericana" se distendió de conflictos políticos y militares con Estados Unidos, la caída de la URSS y la crisis del llamado socialismo real, principalmente, impactaron positivamente - a partir de una definitiva crisis de paradigmas - sobre las fuerzas políticas de izquierdas en la región. El derrumbe de los viejos paradigmas políticos e ideológicos impactó directamente sobre las enquistadas corrientes marxistas ortodoxas y maoístas que dominaron a sectores de la izquierda clásica latinoamericana. Bajo las nuevas condiciones históricas, la crisis de esos "referentes" ideológicos externos, el profundo debate teóricoconceptual en que quedó sumida la izquierda regional y la emergencia de un universo social reaccionando contra el orden imperante - los llamados Nuevos Movimientos Sociales-, impulsaron la búsqueda de alternativas autóctonas, con fundamentos en la cruda realidad circundante.

Poco a poco fue develándose un nuevo escenario político para todas las fuerzas, no sólo de izquierdas, sino de un progresismo que dejó de ser tan ambiguo, y de sectores de la derecha mucho más pragmáticos, porque no podían escapar a las críticas generalizadas ante el desastre causado por los gobiernos neoliberales. De inmediato, comenzaron a gestarse diferentes proyectos políticos, algunos más comprometidos con los Nuevos Movimientos Sociales y una replanteada sociedad civil regional; otros más distantes, pero que tuvieron que aprender a no excluirlos, porque fueron y continúan siendo un factor social indispensable dentro de la actual realidad latinoamericana y caribeña.

Para no extenderse innecesariamente en esta conocida y reconocida realidad, vale resaltar que las nuevas agendas políticas de muchos de los gobiernos triunfantes en las dos últimas décadas han demostrado prestar una mayor atención a sus problemas nacionales y la búsqueda de alternativas para enfrentarlos. Por supuesto, los gobiernos más radicales y otros del progresismo más consolidado han recuperado la figura del Estado y sus instituciones como plataforma imprescindible para revertir la crisis dejada por los gobiernos neoliberales. Sería una pésima omisión no reconocer que esa derecha pragmática mencionada tuvo que aprender de lo que estaba aconteciendo y lo ha demostrado en no pocos proyectos políticos vigentes.

Dediquemos directamente a Cuba el tercero de los eventos a mencionar. Son bien conocidos los dramáticos impactos socio-económicos sufridos en la isla por la caída de la URSS y el campo socialista este-europeo. Más allá de repasar los impac- 
tos económicos, de por sí decisivos para provocar el colapso en cualquier país, hay que insistir en que nos referimos a una pequeña nación subdesarrollada, dependiente económicamente del aliado estratégico que había perdido y bloqueada durante décadas por Estados Unidos, y las consecuencias se hicieron evidentes en todos los ámbitos de la sociedad. Fue la pérdida de aquél que le había suministrado el petróleo cuando le fue negado por Estados Unidos; el que le facilitó el armamento y la asesoría militar, no sólo para su defensa nacional sino para los proyectos emancipatorios en los que se involucró en África y otras regiones del "Tercer Mundo". Fue el aliado estratégico que incorporó al país en el llamado Consejo de Ayuda Mutua Económica (CAME), a través del cual la isla desarrolló casi la totalidad de su comercio exterior y, por tanto, pasó a depender de los suministros externos de toda índole que se consumían en la isla. El mundo socialista que influyó decisivamente en la adopción de escuelas de pensamiento que condicionaron al mundo académico cubano y a toda la vida socio-política del país.

Es la misma URSS que la utilizó como factor de negociación estratégico con su principal adversario durante la "crisis de Octubre"; aunque justo es reconocer - porque no podía ser de otra forma- que logró sacar de aquellas negociaciones con Estados Unidos un acuerdo tácito de no agresión contra la isla. La Unión Soviética que nunca entendió realmente el sentido histórico de las luchas guerrilleras y el "guevarismo". La que debió reconocer el desarrollo de una política exterior tan auténtica y activa como la cubana, que desbordó con creces sus márgenes geográficos y estratégicos, e intentó enseñarle - no siempre con éxito- a su formidable aliado, las esencias originarias del Tercer Mundo. Aquella potencia que, al final de sus días, ya bajo el mando de Mijaíl Gorbachov, abandonó a la Revolución Sandinista y ayudó a la desmovilización final de las fuerzas revolucionarias centroamericanas.

En resumen, la caída de la URSS y sus aliados socialistas europeos significó para Cuba, según cifras oficiales, la pérdida de más del $70 \%$ de su capacidad de compra, que cayó de 8.139 millones de dólares en 1989 a 2.200 millones en 1992 (Granma, noviembre de 1992).

No obstante, hay que reconocer que el gobierno cubano intentó esfuerzos por minimizar, mediante estrategias alternativas, la catástrofe que enfrentaba. En este sentido, hay que recordar los esfuerzos del entonces presidente Fidel Castro por atraer a empresarios latinoamericanos y abrir espacios de comercio con la región, tratando de reinsertar al país fuera de lo que había sido el mundo económico soviético. En esa perspectiva, hay que entender su activismo regional de los años 80 , con su presencia - por ser invitado- en tomas de posesión presidencial de polémicos Presidentes neoliberales como Carlos Salinas de Gortari - México-, Carlos Andrés Pérez - Venezuela-, y Fernando Collor de Mello — Brasil-. En ocasión de su asistencia a la toma de posesión de este último (1990), Fidel Castro declaró a un periodista brasileño: 
Las perspectivas de las relaciones con Brasil son amplias y, como tú dices, ha crecido muchas veces el comercio como la espuma, a partir de nuevos productos que el país está exportando y de una política que hemos seguido: les hemos planteado a los brasileños que todo lo que ellos nos compren a nosotros, sobre todo en cuestiones de medicamentos, vacunas, etc., nosotros se lo compramos en productos brasileños. Es un trueque sin trueque; un trueque a base del compromiso que nosotros mismos hicimos. Les dijimos: no se preocupen por las divisa, que nosotros no les vamos a costar a ustedes una sola divisa, todo lo que ustedes nos compren, vamos a ponerlo en una cuenta especial, y en las mismas cantidades le compraremos productos a Brasil (Castro Ruiz, 1990: 159).

Muchas fueron las razones para esa estrategia: abrirse a nuevos mercados, manejar la falta de liquidez de la economía cubana, evadir las presiones del bloqueo estadounidense y enviar mensajes de nuevas opciones de comercio desde la isla a empresarios de la región, todo ello bajo la convicción de que en la URSS estaba aconteciendo algo que ya nadie podía revertir.

Cuando a la altura de 1993 y reaccionando ante la dramática situación económica que enfrentaba la isla, el gobierno cubano asumió decisiones trascendentales al abrir la economía a modalidades reguladas de inversión extranjera y desatar el desarrollo de la industria turística del país, empresas y empresarios de importantes naciones del hemisferio, como México y Canadá, se hicieron presentes. El caso de Canadá, lleva a la obligada mención a la Sherrit, compañía que lleva ya más de veinte años operando en Cuba, en sectores claves como el petróleo, la minería, la agricultura y el turismo (Kirk y McKenna, 2007: 206-207). Hablamos de un vínculo devenido estratégico, gracias a las estables relaciones construidas con las autoridades cubanas y la protección recibida de parte de su gobierno ante las presiones de Estados Unidos.

México, por su parte, pasó a ser uno de los principales mercados de Cuba, favorecido por las relaciones del gobierno de Carlos Salinas de Gortari (1990-1996) con La Habana. Diferentes intereses económicos de origen mexicano aparecieron en la isla, como el Grupo DOMOS de Monterrey y la Empresa de Cementos de México (CEMEX). Para manejar las presiones del no pago de las deudas a las empresas mexicanas, se adoptó la decisión de ir reduciendo los montos - 350 millones de dólares en 1994, según The Wall Street Journal de agosto de 1994- por medio de swaps, es decir, que el gobierno mexicano vendió parte de la deuda a una compañía nacional, que pasaba a condonar el monto adquirido a cambio de participar en operaciones conjuntas con empresas cubanas (Cubainfo, 1 de Julio de 1994).

Vale recordar que todos estos esfuerzos económicos cubanos y de sus contrapartes estuvieron siempre bajo las presiones no sólo de las leyes y regulaciones del bloqueo, sino de nuevas acciones que buscaban su reforzamiento. En octubre de 1992, el Congreso estadounidense aprobó la Cuban Democracy Act, comúnmente conocida como Ley Torricelli, por su promotor, el congresista Robert Torricelli. Entre sus acápites, la ley reafirmaba los términos del bloqueo, con la adición de 
prohibir las operaciones comerciales de subsidiarias estadounidenses con Cuba (Morales Domínguez y Prevost, 2008: 101-102). Este fue un golpe muy sensible para la economía cubana, porque a pesar de que el monto de ese comercio no rebasaba los 800 millones de dólares anuales, representaba la compra de materias primas estratégicas para el país.

Pocos años después, buscando cortar definitivamente los espacios de comercio que mantenía Cuba con América Latina y Canadá, el gobierno de Estados Unidos reaccionó ante el polémico tema del derribo de avionetas que, provenientes de la Florida, incursionaban en territorio cubano y el Presidente William Clinton firmó en 1996 The Cuban Liberty and Democratic Solidarity Act. La conocida Ley HelmsBurton, - por sus promotores, Dan Burton y Jesse Helms- recrudeció las presiones sobre Cuba, sancionando a toda empresa que comerciara con la isla, bajo nuevos criterios de extraterritorialidad (Morales Domínguez y Prevost, 2008: 104-110).

La crisis de la economía cubana comenzó a reencauzarse a finales de los años 90 , con los primeros resultados obtenidos por los cambios introducidos al interior del país. Pero, indudablemente, el punto de inflexión hay que trazarlo a partir del ascenso a la presidencia de Venezuela de Hugo Chávez, que ya había visitado Cuba a finales de 1994 y había concertado una relación personal con Fidel Castro que se profundizó hasta su prematuro deceso en el año 2013. Con la Venezuela bolivariana de Chávez, luego de superar éste las crisis políticas de 2002 y 2003, Cuba logró un acuerdo preferencial de suministro de petróleo que le permitió solucionar uno de los problemas más críticos a los que se enfrentaba la isla. A diferencia de la génesis de la alianza estratégica cubano-soviética, signada por factores militares y de seguridad, la nueva alianza estratégica cubano-venezolana - sin dejar de significar una nueva dependencia externa- se construyó sobre bases que sobrellevaron más cómodamente las siempre abundantes críticas de sus opositores y detractores. La lógica de la seguridad estratégico-militar del pasado mutó hacia otras lógicas como la seguridad energética, y la seguridad humana, en términos de salud, educación y otros proyectos de índole social que Cuba pasó a desarrollar con Venezuela y le abrieron una nueva época en sus relaciones con América Latina y el Caribe.

\section{Relaciones y no relaciones entre México y Cuba: los claroscuros del camino de la reinserción regional}

El ascenso a la presidencia de México del empresario Vicente Fox en el año 2000 marcó grandes rupturas que partieron desde el interior de la nación mexicana hasta otros senderos al exterior del país. Para México, entre otros factores importantes, lo primero que saltó fue la salida del gobierno del Partido Revolucionario Institucional (PRI), dejando una estela de setenta años de control del gobierno y el poder. Pero, por otra parte, la llegada del Partido Acción Nacional (PAN) al gobierno marcó un llamado de alerta en cuanto al reforzamiento de las relaciones bilaterales con Esta- 
dos Unidos y una gran amenaza para mantener los espacios de independencia y autonomía que tanto habían costado a esa nación. La mirada se fijó de inmediato en las acciones de México como miembro del polémico tratado de Libre Comercio de América del Norte (North American Free Trade Agreement, NAFTA).

Ya fuera de sus fronteras, dentro de nuestro entorno regional, las señales de alarma que habían comenzado a sonar sobre los nuevos rumbos en las relaciones con Cuba se desbordaron, rompiendo con una tradición defendida por los gobiernos prístas desde 1959. Si bien fue bajo el sexenio presidencial de Fox que estalló la crisis, hay que marcar algunos antecedentes. El polémico triunfo electoral del neoliberal Carlos Salinas de Gortari en 1988 marcó una profundización de los caminos que llevarían a México a ser incluido en el NAFTA. Pero ya desde su cuestionado triunfo electoral el gobierno cubano quedó involucrado. Fidel Castro fue invitado a la toma de posesión de Salinas, gesto que para la izquierda tradicional significó la legitimación de un fraude electoral, en una sobredimensión del hecho, expresión de la desesperación política que se vivía ante la incapacidad de revertir lo ocurrido. La posición de Cuba fue coherente con las relaciones históricas mantenidas desde 1959, se respondió a una invitación oficial — gubernamental y no partidista- y se fue muy respetuoso con un principio clave en el pacto no escrito que sostenía los vínculos entre ambos países: la no intromisión en los asuntos internos de la otra parte. Pero eso no apagó el criterio de que la presencia de Fidel había legitimado el fraude. Y como ya se mencionó, Salinas manejó las relaciones con Cuba promoviendo las acciones comerciales antes señaladas. También a nivel internacional las señales de apoyo a Cuba fueron reconocidas:

El gobierno mexicano siguió defendiendo la no intervención en Cuba en las reuniones del Consejo de Derechos Humanos de Naciones Unidas y en las reuniones de líderes latinoamericanos en Madrid (1991-1994), donde países como Argentina exigían apertura política en la isla. Además, México reafirmó su rechazo al embargo estadounidense y específicamente a las leyes Torricelli de 1992 y Helms-Burton de $1996 \mathrm{y}$, a pesar de las presiones de los exiliados cubanos que amenazaron con rechazar la firma del TLC, México no sólo no disminuyó su inversión en Cuba sino que la aumentó (Morales Sod, 2011: 104).

Pero, no todo fue respondiendo a las condiciones especiales que habían determinado las relaciones bilaterales, ya que Salinas recibió a un conocido crítico de la Revolución Cubana, Carlos Alberto Montaner y al poderoso empresario cubanoamericano Jorge Más Canosa, Presidente de la Cuban American National Foundation. Estas acciones sirvieron de preámbulo a las que vendrían.

Ya bajo el gobierno de Ernesto Zedillo (1994-2000), devenido candidato presidencial tras el asesinato político de Luis Donaldo Colossio, se avanzó mucho más no sólo en el manejo de ese segundo carril político abierto por Salinas para manejar la relación con Cuba ante Estados Unidos y la derecha cubano-americana, sino que 
el discurso oficial pasó a mostrar los cambios en el manejo de las relaciones internacionales del país, en una perspectiva en la cual se hacía evidente el cambio en el tratamiento de las relaciones con la isla. Al exponer su Programa de Política Exterior, Cedillo planteó lo siguiente:

- La definición de la soberanía como la capacidad exclusiva de los mexicanos para tomar sus propias decisiones, para diseñar de manera libre y autónoma nuestro proyecto de desarrollo.

- El interés estratégico del país por contar con un entorno de paz y seguridad.

- La utilización de la "diplomacia anticipatoria" como el medio a través del cual México podrá desplegar su proyecto de desarrollo en un entorno pacífico y seguro.

- Diseñar las relaciones con Estados Unidos sobre la base de dos aspectos: primero, un compromiso muy claro con la soberanía de la nación; y, segundo, un reconocimiento a que la madurez alcanzada permitirá continuar con la política de "compartimentalización", es decir, tratar cada tema por separado para no afectar a toda la relación, lo que ha resultado constructivo para ambos países (Bustamante, 1994).

El ascenso de Vicente Fox (2000-2006) abrió un escenario que sobrepasó las esperadas fricciones para pasar al quiebre definitivo de las históricas relaciones. La administración del presidente Vicente Fox, el primero en llegar al poder por un partido distinto al PRI, representó el periodo más difícil de la relación entre México y Cuba. En ese sentido resultó lapidaria la frase expresada por el Canciller Jorge Castañeda G.: "Terminaron los nexos con la Revolución cubana y comenzaron las relaciones con una nueva república" (IPS, 2002).

Castañeda no sólo fue el arquitecto que definió el cambio hacia Cuba sino que fue el autor de la llamada popularmente "enchilada completa", proyecto que bajo esa voz popular significaba la búsqueda de una profundización-recomposición de las relaciones de México con Estados Unidos, contemplando avanzar hacia el llamado NAFTA-Plus, firmar el Acuerdo para la Seguridad y la Prosperidad de América del Norte (ASPAN) y concertar un nuevo acuerdo migratorio, que contemplara la regularización de los indocumentados, la ampliación de visas, un programa de trabajadores huéspedes, medidas para la seguridad fronteriza y acciones de desarrollo regional (Revista Proceso, 2002).

Para no abundar en una historia bien conocida, sólo habría que considerar, por una parte, a un México incorporado al NAFTA, primero, y comprometido posteriormente a ser parte de la nueva lógica estratégica y de seguridad estadounidense post 11-9. Y, por otra, a la emergencia de una nueva generación de políticos mexicanos no sólo del PAN, que defendían esas nuevas relaciones estratégicas con Estados Unidos dispuestos a eliminar o minimizar temas como el de Cuba, que pertenecían a una agenda histórica superada. Por supuesto, esa lectura inicial que 
cometió el error no sólo de distanciarse de Cuba sino de América Latina, fue sometida a un re-análisis gradual con el regreso de los nuevos prístas, tras el binomio panista Fox-Calderón (2006-2012).

Justo es reconocer que Calderón trató de buscar una estabilidad en las relaciones bilaterales, sin regresos al pasado, pero las contradicciones no lograron superarse. Como hechos político-diplomáticos más trascendentes del período quedaron la firma en La Habana, por los entonces cancilleres Felipe Pérez Roque (Cuba) y Patricia Espinosa Cantellano (México), de un Comunicado Conjunto que, más que significar una normalización de las relaciones bilaterales, lo que hizo fue proveer a ambas partes de instrumentos para negociar y canalizar las diferencias. En este sentido, destacaron dentro de su articulado los siguientes puntos:

4. Acordaron celebrar reuniones de los mecanismos bilaterales existentes, en fechas por definir por ambas partes, entre los que figuran las áreas de migración, narcotráfico, comercio y desarrollo industrial, transporte, agricultura y pesca, comercio exterior, turismo, salud, así como la Comisión Mixta de Cooperación para el desarrollo.

5. Las delegaciones examinaron el estado que guardan los tratados en vigor entre los dos países. Las Cancillerías mantendrán el contacto para identificar aquellos instrumentos que requieren ser actualizados. [...]

13. Al analizar el fenómeno migratorio entre ambos países, los Ministros coincidieron en la importancia de avanzar en el establecimiento de un marco jurídico que, con un enfoque integral y bajo el principio de responsabilidad compartida, garantice un flujo migratorio legal, seguro y ordenado (Granma, 14 de marzo de 2008).

Precisamente, este último artículo declaraba la realización de la segunda acción a destacar, el "Memorando de Entendimiento para garantizar un Flujo Migratorio Legal, Ordenado y Seguro", suscrito en octubre del propio 2008 en la Ciudad de México. Dicho acuerdo comprometía a Cuba a "recibir a los inmigrantes ilegales deportados de territorio mexicano, fortalecer los mecanismos para prevenir y combatir la migración ilegal, el tráfico ilícito de personas y la trata, así como todos los delitos asociados a estos" (Aviña, 2009: 55).

Cabe destacar los diferentes encuentros sostenidos entre los mandatarios de ambos países. Felipe Calderón y Raúl Castro se reunieron en dos ocasiones (2008 y 2009). También en dos ocasiones se ha reunido Raúl Castro con Enrique Peña Nieto, siendo la más significativa la visita de éste a La Habana en ocasión de la II Cumbre de la CELAC de enero de 2014.

Precisamente, bajo el mandato de Peña Nieto resalta el énfasis por abrir nuevos espacios a las relaciones comerciales bilaterales. En noviembre de 2013, ambos países acordaron renegociar la deuda cubana contraída con el Banco Nacional de Comercio Exterior de México (BANCOMEX), quedando eximido el gobierno de la isla del pago de aproximadamente 340 millones de dólares de un total de alrededor de 600 millones de dólares. 
En mayo de 2014, 43 empresarios mexicanos visitaron La Habana, abriéndose una oficina nombrada ProMéxico. Por la parte cubana, se estableció como contraparte el Centro de Promoción para el Comercio Exterior y la Inversión Extranjera. En el centro del interés bilateral ha estado, como era de esperarse, la nueva Zona Especial de Desarrollo del Mariel (ZEDM), la cual visitaron.

Para entender las bases actuales de la nueva relación México-Cuba resultan útiles las declaraciones formuladas por dos personalidades que asistieron al mencionado encuentro, Francisco González, Director General de ProMéxico y la subsecretaria de Relaciones Exteriores para América Latina y el Caribe, Vanessa Rubio.

Para González, "se está escribiendo una nueva página de la historia y, por la parte económica, Cuba está manejando el reordenamiento del modelo económico de una forma integral, a largo plazo, muy lógica, paso a paso, que da claridad al empresariado". Mientras que Rubio afirmó que: "su país refrenda y respalda el modelo de actualización que impulsa Cuba y que, a su juicio, se está desarrollando con mucha seriedad, integralidad y sentido de mediano y largo plazo" (EFE, lunes 26 de mayo de 2014).

\section{Cuba y la nueva configuración socio-política regional}

¿Cómo entender a Cuba, el referente histórico de la izquierda latinoamericana, en la nueva coyuntura y en sus relaciones con esos nuevos actores sociales y políticos? Tal vez lo primero que deba decirse es que el mayor aporte de Cuba a la nueva realidad, fue el aprender y aprehender de ella. A partir de esta afirmación resulta entendible que Boaventura de Sousa Santos considere que:

Si es que es cierto que Cuba trató activamente de cambiar el escenario internacional de manera de hacer más justas las relaciones entre los pueblos, también es cierto que los hostiles condicionamientos externos en que la Revolución cubana fue forzada a desarrollarse, impidieron que el potencial de renovación de la izquierda que la Revolución ostentaba en 1959 se realizara plenamente. Tal hecho hizo que la izquierda mundial no se renovara, en los últimos cincuenta años, sobre el legado de la Revolución cubana, sino a partir de otros referentes (Santos, 2009: 1).

Cuando se repasan tanto los contenidos como las raíces históricas de esos nuevos actores sociales y políticos, es perfectamente entendible pero también cuestionable, en alguna medida, tal afirmación. La Revolución cubana reivindicó a generaciones precedentes de luchadores, influyó y formó a otros de su propia generación y se ha mantenido por encima de las coyunturas políticas más adversas, a fuerza de ejercicios de solidaridad que han sobrepasado cualquier otro referente. Y el cuestionamiento viene más desde la perspectiva de entender cuanta diversidad encierra una región como América Latina y, sobre todo, cuánto faltó de comprensión de nuestra 
historia y realidad. De ahí los límites objetivos que lastraron a la influencia soviética. Y la incomprensión de aquellos que esperaron la caída de la Revolución cubana a partir de 1989 y debieron encontrar y aceptar respuestas, que no encontraban ni aceptaban.

Definitivamente, por eso, es que debe entenderse y a la vez cuestionarse una segunda afirmación de Boaventura de Sousa Santos, cuando plantea que para el caso de la Revolución cubana, "la resistencia terminó por superponerse a la alternativa" (Santos, 2009: 1). Por una parte, es muy cierto que el histórico conflicto entre Cuba y Estados Unidos ha gravitado permanentemente sobre toda la sociedad cubana, además de haber marcado la fisonomía de las relaciones de Cuba con sus vecinos durante las tres últimas décadas de Guerra Fría. Pero, por otra parte, sería ingenuo pensar que las relaciones de Cuba con los países que representan la tendencia más radical de las izquierdas hoy han sido las de un simple espectador de los acontecimientos. Una cosa es comprender que estamos refiriéndonos a proyectos políticos que se gestaron sin que mediaran influencias externas, y otra muy distinta es asumir que Cuba no estableciera las más sólidas relaciones posibles con esos nuevos gobiernos. Porque no caben dudas en cuanto a la originalidad y autoría del proyecto venezolano liderado por Hugo Chávez, pero tampoco puede minimizarse la estrecha relación que mantuvo con Fidel Castro, determinando la construcción de una nueva alianza estratégica para la isla.

Daniel Ortega y Lula da Silva, son dos viejos amigos/aliados de la Revolución cubana y sus encuentros, desencuentros y reaproximaciones al liderazgo histórico de la isla se saben muy diferentes. Las relaciones políticas de Daniel Ortega con Cuba reflejan una continuidad Primer Gobierno sandinista $\rightarrow$ Partido político de oposición $\rightarrow$ Segundo Gobierno sandinista, con un perfil mucho mayor que el dirigente brasileño. Eso, además de una larga historia de relaciones que reservan las profundas diferencias surgidas en los diferentes momentos históricos.

Las relaciones de Lula con Cuba se podrían graficar colocándolas, inicialmente, en un punto elevado correspondiente a sus tiempos de líder sindical. Un segundo momento se abrió a partir de la caída del Muro de Berlín y la gestación, por parte de Fidel y Lula, de lo que sería posteriormente el Foro de São Paulo, evento crucial para generar una recomposición histórica de la izquierda latinoamericana, reuniendo en octubre de 1992 a más de cien organizaciones y movimientos políticos de ese signo.

El tercer momento de las relaciones de Lula con Cuba se abrió, obviamente, tras el ascenso a la Presidencia de Brasil. Es bien conocido el rol desempeñado por Lula en la búsqueda de la reinserción plena de Cuba en la comunidad regional y su personal impronta en la definición del estratégico proyecto del puerto cubano de Mariel. Sobre Lula, que sin lugar a dudas es el político brasileña más relevante en lo que va del presente siglo, resulta muy ilustrativa la visión que nos brinda Emir Sader: 
Componentes de la izquierda anterior y de corrientes internacionales hicieron de Lula no sólo un dirigente obrero clasista, vinculado a las tradiciones de los consejos obreros, sino un dirigente de un partido de izquierda gramsciano, de un nuevo tipo, democrático y socialista. Lula no era nada de eso, pero tampoco era un dirigente a imagen y semejanza de aquello en lo que se había convertido el PT. Se formó como dirigente sindical, de base, en la época en que los sindicatos estaban prohibidos por la dictadura; un dirigente negociador directo con las entidades patronales, un gran líder de masas, pero sin ideología. Nunca se sintió vinculado a la tradición de la izquierda, ni a sus corrientes ideológicas, ni a sus experiencias políticas históricas. Se afilió a una izquierda social — si podemos considerarla de ese modo-, sin tener necesariamente vínculos ideológicos y políticos con ella. Buscó mejorar las condiciones de vida de la masa trabajadora, del pueblo o del país, según su vocabulario se fue transformando a lo largo de su carrera. Se trata de un negociador, de un enemigo de las rupturas, por lo tanto, de alguien sin ninguna propensión revolucionaria radical (Sader, 2009: 4).

Néstor Kirchner (Argentina), Evo Morales (Bolivia) y Rafael Correa (Ecuador), no tienen una relación histórica con Cuba. Se sabe que Kirchner fue una figura emergente dentro del peronismo, acogida por la población para impedir un nuevo ascenso a la presidencia de la nación del neoliberal Carlos Saúl Menem. Una acertada fotografía política de lo ocurrido en la Argentina durante la coyuntura crítica de 2001-2002, quedó plasmada en las siguientes reflexiones de Carlos Vilas:

Es posible emparentar los sucesos de diciembre de 2001 en Argentina con acontecimientos de protesta masiva escenificados recientemente en otros países de América del Sur. Tanto por el papel que en todos ellos desempeñaron esquemas de política y ajuste macroeconómico inspirados de una u otra manera en el llamado Consenso de Washington, y en los objetivos e intereses de las élites del poder económico y financiero, como por la virulencia del desborde popular ante la deslegitimación de los sistemas políticos respectivos. Y también por la capacidad del viejo sistema político de procesar la crisis y reorientar y neutralizar la protesta masiva cuando el cuestionamiento social no alcanza una expresión política propia y no muestra capacidad de avanzar desde el rechazo - momento inicial imprescindible de cualquier búsqueda de una alternativa - hasta la formulación de propuestas viables (Vilas, 2005: 264265).

Con Argentina y la era de gobiernos iniciada por Kirchner se debe partir de entenderlos dentro del nuevo espectro del progresismo - contenido dentro de las izquierdas-, quedando condicionados sus niveles de "izquierdismo" a la necesidad de dar respuestas creíbles a una población que se lanzó a las calles contra todos los políticos, a la crítica situación interna que heredó y a las nuevas dinámicas políticas que se han abierto paso en la región, respondiendo a un momento político muy diferente del pasado. Las relaciones con Cuba son un ejemplo a estudiar, una agenda bilateral marcada por los patrones tradicionales de distanciamiento; apertura de 
espacios tangenciales en términos de pequeños negocios, combinada con algunos intercambios culturales y científico-técnicos, y un manejo del discurso político, evitando fricciones con los sectores de poder argentinos más conservadores. Si bien es cierto que se distendieron más las relaciones con el gobierno de Cristina Fernández, en lo que a Cuba respecta, Argentina siempre ha manejado sus relaciones con la isla a la zaga tanto de los gobiernos más radicales (Venezuela, Bolivia, Ecuador y Nicaragua) como del propio Brasil.

Evo Morales, un líder cocalero, devenido en presidente del Estado Plurinacional de Bolivia, ha demostrado ser un sólido amigo y aliado del gobierno cubano. Ha sido evidente la redefinición de las relaciones políticas con Cuba bajo su gobierno, incluyendo proyectos de colaboración en esferas como la salud, la educación y el deporte, colocándolas en niveles de identificación nunca antes alcanzados. Evo vendría a ser la expresión más alta de las relaciones del gobierno cubano con los movimientos indígenas de la región. El caso boliviano también amerita la atinada reflexión de Emir Sader, quien nos remite a la búsqueda de una comprensión del actual proceso político en ese país, ponderando la decidida participación de un "núcleo duro de pensamiento", el Grupo Comuna (Álvaro García Linera, Luis Tapia, Raúl Prada, entre otros), que aportaron los fundamentos teóricos que necesitaba un proyecto de raíz indígena para triunfar por encima de la historia regional. Para Emir Sader:

[...] El Grupo Comuna supo hacerlo porque releyó la historia boliviana, en especial a partir de la Revolución de 1952, descifró su significado, hizo las periodizaciones posteriores de la historia del país, comprendió los ciclos que llevaron al agotamiento de la fase neoliberal, consiguió deshacer los equívocos de la izquierda tradicional en relación con los sujetos históricos y realizó el trabajo teórico indispensable para concertar el casamiento entre el liderazgo de Evo Morales y el resurgimiento del movimiento indígena como protagonista histórico esencial del actual período boliviano. Pudo así recomponer la articulación entre la práctica teórica y la política, y ayudar al nuevo movimiento a abrir los caminos de lucha por las reivindicaciones económicas y sociales en los planos étnico y político (Sader, 2008: 6-7).

Rafael Correa, por su parte, llegó a la presidencia de Ecuador, un país que lastra una profunda fragmentación política desde la última década del siglo XX, por caminos muy diferentes. Tres han sido sus capacidades esenciales, su sólida formación académica que le ha llevado a ser un convencido anti-neoliberal; su capacidad política para gerenciar un panorama político nacional tan complejo, y la clara definición de metas políticas que le han permitido alcanzar resultados reconocidos de su llamada Revolución Ciudadana.

Con toda intención, se ha dejado para el final el caso de las relaciones entre Venezuela y Cuba. Al analizar la trayectoria de Hugo Chávez aparecen semejanzas históricas que explican, en buena medida, cómo llegó a concertar una alianza estratégica de tanta envergadura como la que sostuvo con Fidel Castro, legada a sus 
sucesores. Un primer elemento de convergencia, sin desconocer las particularidades de ambos líderes, es el rol militar que tanto Fidel como Chávez ejercieron y desempeñaron. Fidel no era un militar de carrera, pero su vida, primero en la lucha guerrillera y después tras el triunfo de la Revolución, ha sido bajo el símbolo y la praxis del Comandante en Jefe. Chávez, un militar de carrera, teniente coronel, fue electo democráticamente como Presidente, pero su imagen política estuvo siempre explícitamente asociada al líder militar. Para ambos líderes, la lógica de sus proyectos políticos fue la alianza cívico-militar.

Un segundo elemento está en la génesis de sus respectivos liderazgos, al conjugarse una formación ideológica nacionalista-antiimperialista, radicalizada posteriormente hacia el socialismo. Se sabe que Fidel fue más un convencido martiano, como Bolívar fue siempre el paradigma político de Chávez.

Como tercer elemento, ambos líderes encabezaron movimientos políticos al margen de la fisonomía de los partidos tradicionales. Crearon movimientos políticos teniendo muy claro las limitaciones de las izquierdas históricas de sus respectivos países. Durante sus procesos de lucha (guerrillera/militar y política) por alcanzar el gobierno en sus respectivos países, mantuvieron relaciones controladas con los partidos tradicionales de izquierdas y, finalmente, impusieron unos partidos políticos - comunista/socialista - a los cuales esas fuerzas tradicionales debieron sumarse o separarse definitivamente.

El cuarto elemento compartido fue su vocación latinoamericana y caribeña, con las consabidas implicaciones para las relaciones con Estados Unidos, más allá de las diferencias históricas. Cerremos con una interrogante final. Conociendo la personalidad e ideas políticas defendidas por Chávez, ¿quién si no la Revolución cubana de Fidel Castro podía ser su principal referente de izquierda en la región?

\section{Cuba, Estados Unidos y la VII Cumbre de las Américas}

Posiblemente, aquellos que no siguieron los acontecimientos de la V Cumbre de las Américas celebrada en Trinidad y Tobago en abril de 2009, se hayan sorprendido del peso que tuvo en su agenda el tema de Cuba. Debe recordarse que ya durante su campaña electoral, Barack Obama había planteado sus intenciones de revisar las políticas hacia Cuba, coincidiendo con importantes decisiones sobre las relaciones con la isla que se adoptaban en América Latina. A finales de 2008, el Grupo de Río aprobó la definitiva inclusión de Cuba en la organización, adicionando la petición formal al gobierno de Estados Unidos de levantar el bloqueo a la isla y la invitación a que ambos países se sentaran a negociar sus diferencias.

Al concluir el primer semestre de 2009, con la presencia de nuevos Presidentes en El Salvador y Costa Rica, Cuba pudo normalizar sus relaciones con ambos países a nivel de Embajadas. Eso implicó que el gobierno cubano logró restablecer sus vínculos diplomáticos con todos los países latinoamericanos y caribeños, tras 50 
años de aislamiento, reencuentros casuísticos y constantes rupturas. De inmediato, dentro de la opinión pública internacional se acuñó el criterio de la reinserción plena de la isla en la comunidad regional y, para muchos, el brillo de los fuegos artificiales de la noticia, dejó opacado el necesario y más mesurado análisis que se imponía.

El hecho en sí resumía el balance de medio siglo de historia bilateral, marcado por los importantes cambios ocurridos tanto a nivel internacional como en el hemisferio. Fue una decisión soberana de los gobiernos latinoamericanos y caribeños, independiente de las consideraciones del gobierno de Estados Unidos. Pero, ¿podía asumirse que la posición alcanzada tenía la suficiente solidez como para resistir y sortear todas las diferencias existentes entre Cuba y la mayoría de sus vecinos? América Latina asumió definitivamente el apoyo a Cuba en la demanda de la suspensión del bloqueo estadounidense y también el gobierno cubano dejó de ser enjuiciado por algunos de sus vecinos con los polémicos temas sobre derechos humanos y democracia. ¿Cambiaron los tiempos?, ¿las prioridades nacionales?, ¿preocupación por los tantos tejados de vidrio que pueden romperse por el "efecto boomerang"?, ¿se ha llegado a la comprensión de la necesidad de alcanzar una nueva concertación política regional? Definitivamente, mediaron estos y otros argumentos encaminados hacia la búsqueda de la reinserción definitiva de Cuba en América Latina y el Caribe, bajo mejores condiciones, en la nueva y muy complicada realidad global de la Posguerra Fría.

Como afirmó Gabriel Aguilera, avezado político y académico guatemalteco:

Hoy, a diferencia de la posición mayoritariamente anticomunista y anticubana de los 60, predomina en América Latina un clima que va desde la tolerancia hasta el apoyo decidido a Cuba. Al mismo tiempo, los márgenes de autonomía respecto a la política de Estados Unidos se han ampliado y no tienen comparación con los del siglo pasado (Aguilera, 2009: 5).

Tenemos, por tanto, una evidente reinserción plena político-diplomática y una apertura gradual, sostenida, de las relaciones económicas con la región, siendo los países del ALBA-TCP, Brasil y México, los principales socios de la isla. Y, en medio de este escenario, Cuba cambiando por sí misma.

El 5 de diciembre de 2014 la cancillería del gobierno de Panamá comenzó a enviar las invitaciones oficiales para participar en la VII Cumbre de las Américas a celebrarse en ese país los días 10 y 11 de abril de 2015. Ya en el mes de septiembre de 2014, José Miguel Insulza, Secretario General de la OEA, había planteado la pertinencia y utilidad de la participación del gobierno cubano y pareció que el propio gobierno estadounidense en la persona del Secretario de Estado John Kerry, dejó de colocarlo como un obstáculo ante la Cumbre. Con eso se afirmó un precedente pre-Cumbre que se descubrió totalmente con los acontecimientos del pasado 17 de diciembre. 
Todo hacía pensar que, al margen de lo ocurrido el 17-D, Cuba iba a asistir por primera vez a una Cumbre de las Américas. A la formal invitación del gobierno de Panamá, se sumaron las importantes declaraciones emitidas por el mandatario de Costa Rica Luis Guillermo Solís, actual Presidente pro-témpore de la CELAC:

Ya el tema de Cuba hay que mirarlo con otros ojos. Creo que la normalización de Cuba en la OEA, aunque Cuba ha tomado la decisión de no participar en ese foro, la presencia de Cuba en la Comunidad de Estados Latinoamericanos y Caribeños (CELAC), habiendo sido su Presidente pro-témpore, y la relación que tiene con todos los países de América Latina sin excepción, hace obligatoria también la presencia de Cuba en otras esferas en donde están presentes gobiernos como el de Estados Unidos, que no tiene relaciones con Cuba. [Y agregó,] no veo cómo se podría evitar esa presencia ni tampoco vería cuál sería el beneficio de la ausencia de Cuba en las reuniones hemisféricas. Creo que debe de estar y me parece normal que esté presente en todas ellas (El País, 5 de diciembre de 2014).

El período que medió entre ese 17 de diciembre y el inicio de la VII Cumbre de las Américas de Panamá (10-11 de abril de 2015), destacó más por los complicados manejos, debates y defensas de las decisiones asumidas por ambos gobiernos al interior de sus sistemas políticos, que por los resultados de las conversaciones oficiales sostenidas, sin negar la magnitud de las mismas ni los precedentes que, poco a poco, fueron rompiéndose. Este es un aspecto medular y habría que ser extremadamente ingenuo para suponer que los problemas fueron sólo para Obama y los sectores políticos que apoyaron su decisión.

Otra perspectiva del análisis, siempre manejada, va por el camino de preguntarse ¿cuál de los dos países asume los mayores costos con tal decisión? En realidad, la ecuación podría verse entre una nación - la cubana, obviamente y no sólo en la isla, de una parte- y un conjunto de sectores del poder económico y político estadounidenses, mayoritariamente demócratas, de la otra.

Tanto en debates académicos como en espacios informales es común escuchar que la "relación conflictual distante", sostenida con Estados Unidos durante tantos años, ha tenido todos los costos económicos, políticos y sociales conocidos pero, congelados los escenarios de agresión militar directa, la apertura al diálogo para restablecer relaciones diplomáticas presenta nuevos y muy peligrosos desafíos para el gobierno cubano. Las relaciones entre Estados Unidos y Cuba son, a no dudarlo, un tema crucial que atraviesa el magno tema de la nación cubana. Las razones son múltiples: económicas, políticas, históricas, culturales, geográficas y sociales —con la constante e incontrolable interacción entre los cubanos de la isla y los cubanos y sus descendientes residentes, sobre todo, en Estados Unidos-.

Para Obama el problema es esencialmente político - sin desconocer factores económicos y de otra índole-; para Cuba es un problema nacional, entendido desde la perspectiva de que lo incluye todo. Desmontar una psicología política del enemigo permanente - tanto para los que lo creen honestamente como para los que 
tienen secretamente otras ideas-, abriéndose la responsabilidad interna de comenzar a construir una nueva psicología, con un fuerte peso en las nuevas generaciones. A criterio de este autor, esa nueva psicología política no debe desentenderse de presupuestos como la defensa de la soberanía, la independencia nacional, la identidad nacional, y del conjunto de conquistas sociales de la Revolución, que, más allá de las carencias y deficiencias acumuladas, significan reales avances para cualquier sociedad.

El proceso de negociaciones bilaterales será definitorio para decidir el modelo de relaciones que podrán construir, siendo esencial el dejar de lado la lógica de suma cero que ha predominado. Mientras se perciba que yo gano porque tú pierdes no se avanzará del discurso a los hechos. Y no puede desconocerse un factor esencial, Cuba está abocada a una transición de liderazgo histórico hacia otro, sobre el que se especula mucho pero no existen certezas. Y, a no dudarlo, este es un argumento central para Obama y sus seguidores. Cabe pensar que más allá de las reales motivaciones de intentar reposicionarse en un mercado económico asumido siempre como suyo, los principales intereses en juego son políticos o, mejor dicho por su esencia histórica, geopolíticos.

Algunas de las primeras lecturas que saltan de la VII Cumbre de las Américas recién concluida en Panamá, hacen pensar en un Obama que, si bien mostró su habilidad política durante el foro, cargaba con los errores - bienintencionados o no- de sus asesores sobre la absurda decisión de declarar a Venezuela como una amenaza a la seguridad nacional de Estados Unidos. Para Cuba fue un triunfo total; Venezuela se oxigenó en la Cumbre, ayudada por los errores estadounidenses; y quedó demostrado que América Latina y el Caribe ya sabe organizar Cumbres, decirse todas las diferencias que cargan en sus discursos presidenciales y mantener, paralelamente, la capacidad de elaborar documentos finales consensuados. Eso, es una gran asignatura pendiente para Estados Unidos, es decir, para las Cumbres de las Américas.

En cuanto al polémico Foro de la Sociedad Civil, quedó en evidencia la pésima actuación de los organizadores del evento. Se prestaron para facilitar una triste batalla, con las peores y más viejas armaduras, de una guerra ya perdida. Este juego, a su manera habitual, también lo ganó Cuba.

Salvando las distancias, si Estados Unidos no puede faltar a la Cumbre, América Latina y el Caribe necesita que Cuba también esté presente. Y esto debemos asumirlo sin sobredimensionamientos, está claro que para los gobiernos aliados y amigos de Cuba la defensa de la presencia oficial de la isla pasa por sus agendas políticas. Pero una lectura regional podría argumentarnos que se viven tiempos de consensos esenciales sobre temas tan sensibles como la defensa de la soberanía nacional, la maximización de las autonomías y el replanteamiento de las dependencias, y esos temas, de una u otra forma, serán defendidos por todos.

Y para eludir un rosario de razones que podemos encontrar entre los países latinoamericanos y caribeños podría afirmarse, resumiendo, que la región en la Posgue- 
rra Fría, por una parte tuvo que reaccionar ante los nuevos desafíos que le impuso el nuevo escenario global; tuvo que reconfigurarse social y políticamente; tuvo que aprender a aceptar las nuevas experiencias que nacieron desde la izquierda; y también tuvo que aprender a aceptar a Cuba, porque aprendió mucho de ella. La vio resistir, sobrevivir a la debacle soviética, insertarse en la dinámica de cambios en la región y comenzar a cambiar, por sí misma. Y qué mejor colofón que escuchar al Presidente de Estados Unidos reconocer que las políticas aplicadas hacia la isla por más de cincuenta años habían sido un fracaso. Si histórica fue la decisión del 17 de diciembre, no menos histórica resultó la Cumbre de las Américas de Panamá.

\section{Las relaciones entre Estados Unidos, América Latina y el Caribe: presente y futuro}

A Panamá se debió ir a buscar la construcción de una Nueva Vecindad, no del Norte, ni sólo del Sur, sino, necesariamente, de ambas partes. No hablemos de ganadores y perdedores, aunque los hubo. En base a esto, pensemos que Obama tenga conciencia de que hoy, porque la OEA no lo garantiza, la Cumbre de las Américas es el único foro hemisférico que le facilita al Presidente de Estados Unidos una interlocución directa con sus pares de la región. Lamentablemente, no parece que Obama haya considerado la dimensión estratégica de esta Cumbre, más allá del interés estratégico que reviste hoy la búsqueda de un restablecimiento de relaciones con Cuba.

Porque, si bien la VII Cumbre de las Américas dejó el buen sabor del inicio del diálogo entre Cuba y Estados Unidos, el gran tema pendiente es la construcción de una nueva agenda interamericana. Junto al ya mencionado cambio de estrategia de Estados Unidos hacia la región en la Posguerra Fría, en una lógica que ha apuntado más hacia el tratamiento de casos y temas (Libre Comercio, México, Cuba, Venezuela, narcotráfico, etc.) se aprecia que ese país ha dejado de ser el único actor definitorio externo para América Latina y el Caribe. China, sobre todo, pero también Rusia, India y la Unión Europea, cada quien con sus particularidades y distancias, están pasando a ocupar mercados estratégicos de la región. Préstese atención a la siguiente reflexión:

La declinación irreversible de EE UU ya se pronosticó otras veces y otras tantas la potencia recuperó el lugar que parecía haber perdido. Pero esta vez hay diferencias cardinales con otras coyunturas del pasado, que sugieren un cambio cualitativo en sus vínculos con América Latina. La contracción relativa de los flujos de comercio de la región con EE UU - en particular, los de Sudamérica- es un dato duro. Sudamérica diversificó sus opciones comerciales y no depende de la ayuda ni de los flujos financieros del BID o del BM. El Banco Nacional de Desarrollo de Brasil (BNDES) es más grande que estas dos instituciones; la Corporación Andina de Fomento (CAF) se 
consolidó como institución financiera regional, y América del Sur fortalecerá tarde o temprano su propio Fondo de Reservas. Si el FMI actúa en el futuro, sin duda ya no podrá usar los mecanismos ni las recetas tradicionales (Fernández, 2013: 85).

Resulta irónico que ayer la URSS, una potencia extra-continental - término muy presente en los documentos doctrinales de la OEA y el TIAR-, mantuviese encendido el botón de alarma sobre las amenazas a la seguridad nacional de Estados Unidos y de la región. Hoy, sin tener que ayudar a subvertir gobiernos porque ya cambiaron por sí mismos, el Gran Dragón chino sostiene un comercio con la región que sobrepasa los 200.000 millones de dólares en conjunto (comercio, inversiones, proyectos), incluida la construcción de un nuevo canal interoceánico - un histórico tema de conflicto para Estados Unidos, hasta que lo logró en Panamá- y las alarmas no sabemos si están sonando, porque las respuestas de ayer eran mucho más fáciles que las que se demandan hoy.

Pero las grandes distancias que se abren entre Estados Unidos y la región no marchan sólo por esos rumbos. El Sistema Interamericano debe se - porque no es sólo la OEA, es el TIAR y mucho más-, y no ver en la nueva institucionalidad latinoamericana y caribeña una amenaza o un enemigo; es una consecuencia histórico-lógica de lo que ha sido el Sistema Interamericano para la región y del "cambio de época" que ha identificado Rafael Correa.

La CELAC no pretende matar a la OEA, porque sus rumbos marchan más hacia un dramático estado de coma autoinfringido (El País, 2 de enero de 2015). La OEA no necesita ser defendida, lo que demanda es de un replanteamiento radical, desde sus conceptos esenciales. Ni remiendos ni reparaciones, tiene que cambiar de época, como lo ha hecho América Latina y el Caribe.

Nada ni nadie puede borrar la historia y los garrafales errores cometidos por y desde la OEA —a sabiendas de quién o quiénes manejaban los hilos del poder-, pero si no se entiende que la nueva institucionalidad latinoamericana no puede desentenderse de reacciones contra la vieja e inoperante institucionalidad que representa la OEA, se está muy alejado de la realidad.

En el entorno del golpe militar efectuado en Honduras en julio de 2009, derrocando al Presidente constitucional de ese país, Manuel Zelaya, el periodista Andrés Oppenheimer citó las siguientes declaraciones de Dante Caputo, excanciller argentino y entonces Asesor del Secretario General de la OEA, José Miguel Insulza. Para Caputo: "Puede consolidarse la idea de que estamos frente a un nuevo tipo de golpe, un golpe correctivo, que no pretende una permanencia en el poder por años sino bloquear una acción presidencial [ilegal] y relanzar el juego democrático a los pocos meses" (Oppenheimer, 2009).

¿Podían tales declaraciones satisfacer a los países latinoamericanos y caribeños? ¿Qué estaba legitimando Caputo, el precedente? Irónicamente, la acción que supuestamente originó el golpe contra Zelaya - todos sabemos que fue realmente por su acercamiento a Hugo Chávez y al ALBA - hoy ha sido acreditada por el Con- 
greso hondureño. Por supuesto, no estamos ante escenario de una reelección presidencial de Zelaya ni de las fuerzas políticas progresistas de ese país.

Resumiendo, el desconocimiento de la nueva institucionalidad latinoamericana y caribeña se facilitó por los gobiernos de izquierdas que asumieron el poder en diferentes países, pero es aceptada, en su esencia - léase UNASUR y CELACpor todos. El defender una articulación expresa entre el desgastado Sistema Interamericano - desde los esenciales cambios que requiere- y esta nueva institucionalidad latinoamericana y caribeña podría haber sido una estrategia exitosa para Obama y un paso crucial para Estados Unidos con sus vecinos del Sur.

Como bien afirmó Marco Albuja, Representante Permanente de Ecuador ante la OEA:

La OEA en su momento sirvió para la promoción de los intereses geopolíticos de EE UU, sirvió para la represión o para tapar la represión; y luego, por tratar de olvidar ese pasado, fue directamente a la inercia, a la inacción [...] El plan de trabajo de Almagro [...] está concentrado en el ser humano, y en cómo avanzar en el desarrollo, la salud y la educación, la seguridad y la paz, la estabilidad económica y social, y los derechos humanos [...] Creo que es la última esperanza para tener una OEA que funcione. La otra característica de Almagro que ha gustado mucho es que habla de la complementariedad con UNASUR, MERCOSUR, SICA, CARICOM y CELAC; no se trata de pelear espacios de poder, ni siquiera espacios de desarrollo. La OEA debe cumplir su parte, y el resto de las tareas ser emprendidas desde esos otros espacios (Karg, 2015: 2).

Hasta los gobiernos más radicales de América Latina y el Caribe saben que necesitan de un foro en donde dialogar, directamente, con Estados Unidos. Por eso la supervivencia de las Cumbres de las Américas y la obligatoriedad de asumir profundos cambios en el Sistema Interamericano. Se debe prestar atención en este sentido al programa de campaña electoral del recién electo Secretario General de la OEA. Aparte de los temas sobre democracia y derechos humanos, que no podían faltar, y no pueden quedar marginados de los necesarios nuevos enfoques, las propuestas de Almagro sobre la multidimensionalidad de la seguridad resultan sumamente sugerentes. Pero, ¿cómo enfocaría el tema?, ¿seguridad energética? Se la ofrece PetroCaribe al Caribe anglófono. ¿Seguridad medioambiental? Le pondría al Presidente Rafael Correa las herramientas que necesita contra las transnacionales y a otros tantos actores oficiales y no oficiales el argumento para cargar contra las compañías extractoras canadienses que enfrentan numerosas demandas en la región. ¿Seguridad alimentaria? ¿Acaso no sería un buen argumentos para que la demanda de derogación del bloqueo a Cuba y la supresión de la guerra económica interna en Venezuela se posesione dentro de una nueva agenda regional de la OEA?

Con la Cumbre de Panamá se abrió un nuevo e interesantísimo escenario interamericano, pero no puede desarrollarse mientras unos protagonistas sigan viviendo en el pasado y otros avancen aceleradamente hacia un nuevo presente. 


\section{Bibliografía}

Aguilera Peralta, Gabriel (2009) "Cuba y la OEA. Apuntes de una larga y complicada relación". Revista Nueva Sociedad, núm. 223, 4-14 [URL: $<$ www.nuso.org $>$. Consultado el 10 de Enero de 2015].

Avila, Jim, y Keneally, Meghan (2015) "President Asks Congress to Lift the Embargo Against Cuba". ABC News, 20 de enero. [URL: $<\mathrm{http} / / /$ abcnews.go.com/Politics/president-congress-lift-embargo-cubasources/story?id=28358404>. Consultado el 15 de febrero de 2015].

Aviña, Camila (2009) "Perspectivas en la relación bilateral México-Cuba: de la fractura al reencuentro". Espacio Laical, La Habana [URL: $<$ http://www.espaciolaical.net/contens/17/5355.pdf $>$. Consultado el 7 de Enero de 2015].

Bustamante, Jorge A. (1994) "Consideraciones de Política Exterior", en PRI. Programa de Política exterior: Una propuesta de Ernesto Zedillo Ponce de León. México: Comisión de asuntos Internacionales del CEN del PRI.

Castro Ruiz, Fidel (1990) Fidel en Brasil. Selección de Intervenciones. La Habana: Editora Política.

Fernández, Gustavo (2013) "Espejos y espejismos: las relaciones entre América Latina y Estados Unidos". Nueva Sociedad, núm. 246, 78-86 [URL: $<$ www.nuso.org $>$. Consultado el 10 de Abril de 2015].

IPS (2002) "México-Cuba: el pragmatismo que acerca y enfría". Agencia de Noticias Interpress Service, 9 de febrero. [URL: $<$ http://www.ipsnoticias.net/2002/02/integracion-y-desarrollo-cuba-mexico-elpragmatismo-que-acerca-y-enfria/>. Consultado el 20 de Enero de 2015].

Karg, Juan Manuel (2015) "Entrevista a Marco Albuja, Representante de Ecuador ante la Organización de Estados Americanos". Rebelión [Puesto en línea el 10 de Marzo de 2015. URL: <http://www.rebelion.org/noticias/2015/3/196265.pdf>. Consultado el 12 de Abril de 2015].

Kirk, John M., y McKenna, Peter (2007) Canadá y Cuba. Sesenta años de relaciones bilaterales. La Habana: Editorial Ciencias Sociales.

Morales Domínguez, Esteban, y Prevost, Gary (2008) United States-Cuban Relations. A Critical History. Nueva York: Lexington Books.

Morales Sod, Gabriel (2011) "La relación entre México y Cuba: de la no intervención al «comes y te vas»". Gaceta de Ciencia Política, vol. 8, núm. 1, 97-106.

Oppenheimer, Andrés (2009) “¿Qué va a pasar en Honduras?”. El Nuevo Herald, 9 de septiembre.

Revista Proceso (2002) "Sobre el acuerdo migratorio, no habrá enchilada completa: Castañeda", Revista Proceso (México), núm. 192, 10 de enero.

Sader, Emir (2008) “¿Por dónde anda el otro mundo posible?”. Contexto Latinoamericano. Revista de Análisis Político, núm. 7 [Puesto en línea el 3 de Marzo de 
2008. URL: $<$ http://www.contextolatinoamericano.com/articulos/por-dondeanda-el-otro-mundo-posible/\#>. Consultado el 12 de Septiembre de 2014].

Sader, Emir (2009) "Izquierda social y política: la orfandad de la estrategia". Centre Tricontinental, 4 de septiembre [URL: $<$ http://www.cetri.be/spip.php?article1317>. Consultado el 14 de Abril de 2015].

Santos, Boaventura de Sousa (2009) "¿Por qué Cuba se ha vuelto un problema difícil para la izquierda?". Rebelión, 20 de enero [URL: $<$ http://www.rebelion.org/noticia.php?id=83540>. Consultado el 14 de Abril de 2015].

Vilas, Carlos M. (2005) "Pobreza, desigualdad y sustentabilidad democrática: El corto ciclo de la crisis argentina". Revista Mexicana de Sociología, vol. 67, núm. 2, 229-269. 